Article

\title{
Precipitate Evolution and Fatigue Crack Growth in Creep and Artificially Aged Aluminum Alloy
}

\author{
Chi Liu ${ }^{1}$, Yilun Liu ${ }^{1}$, Liyong Ma ${ }^{2, *}$, Songbai Li ${ }^{1}$, Xianqiong Zhao ${ }^{1}$ and Qing Wang ${ }^{1}$ \\ 1 College of Mechanical and Electrical Engineering, Central South University, Changsha 410083, China; \\ liuchi001@csu.edu.cn (C.L.); yilunliu@csu.edu.cn (Y.L.); csulsb@csu.edu.cn (S.L.); csuzxq@csu.edu.cn (X.Z.); \\ ldlgwq@csu.edu.cn (Q.W.) \\ 2 School of Mechanical Engineering, Hebei University of Architecture, Zhangjiakou 075051, China \\ * Correspondence: maliyong@csu.edu.cn; Tel.: +86-189-3263-7968
}

Received: 8 November 2018; Accepted: 4 December 2018; Published: 7 December 2018

check for updates

\begin{abstract}
The fatigue performance of high-strength $\mathrm{Al}-\mathrm{Cu}-\mathrm{Mg}$ alloys is generally influenced by the process of creep age formation when applied to acquire higher strength. The results show that creep aging accelerates the precipitation process, leading to a more uniform precipitation of strengthening phases in grains, as well as narrowed precipitation-free zones (PFZ). Compared with the artificially aged alloy, the yield strength and hardness of the creep aged alloy increased, but the fatigue resistance decreased. In the low stress intensity factor region $\left(\Delta K \leq 7 \mathrm{MPa} \cdot \mathrm{m}^{1 / 2}\right)$, the fatigue crack propagation (FCP) rate was mainly affected by the characteristics of precipitates, and the fatigue resistance noticeably decreased with the increased creep time. In a $4 \mathrm{~h}$ creep aged alloy, the microstructure was dominated by $\mathrm{Cu}-\mathrm{Mg}$ clusters and Guinier-Preston (GP) zones, while $\mathrm{S}^{\prime \prime}$ phases began to precipitate in the matrix, showing better fatigue resistance. After aging for $24 \mathrm{~h}$, the needle-shaped $\mathrm{S}^{\prime}$ phases were largely precipitated and coarsened, which changed the mode of dislocation slip, reduced the reversibility of slip, and accelerated the accumulation of fatigue damage. In stable and rapid crack propagation regions, the influence of precipitates on the FCP rate was negligible.
\end{abstract}

Keywords: precipitates; fatigue crack growth; creep aging; artificial aging

\section{Introduction}

A new aerospace high-strength Al-Cu-Mg alloy called AA2524, developed after the 2024 and 2124 aluminum alloys, exhibits excellent fatigue resistance [1-3]. Combined with creep age forming (CAF) technology, currently, AA2524 primarily finds its application in the manufacturing of wing coverings, fuselage panels, and other components [4,5], e.g., the upper wing skin of civil aircrafts such as the Airbus A330/340/380 [6], the wing panels of military aircrafts such as the B-1B bomber, C-17, and F-35 [7], as well as tank panels and melon petals in the American Saturn-5, Hercules-4, and Ariane-5 launch vehicles of the European Space Agency $[4,8]$. Creep age formation is a process that takes advantage of the creep property of metals to synchronize the forming and aging treatments. The formed products achieve excellent structural integrity and low residual stress [9-12]. Many scholars have conducted substantial research on the mechanical properties and springback prediction of creep aged materials. Zhan et al. [10] established a creep constitutive model and analyzed the relationship between the change of stress and precipitates and the aging strengthening in the creep aging process. Jeshvaghani et al. [13] asserted that for a 7075 aluminum alloy that has been creep aged at high and low temperatures in sequence, the springback rate decreased, and the exfoliation corrosion resistance was improved. Xu et al. [14] researched the creep aging behavior of AA2524 with the presence of pre-strain. The results showed that the increase of pre-strain can reduce the average size of $S$ phases 
in the creep aged alloy and increase its density and uniformity, leading to a shortened time for peak aging and improved strength.

The current research on creep aged alloys focuses mainly on conventional mechanical properties and less on the fatigue properties. Influenced by frequent takeoff, landing, and airflow, creep aging-formed fuselage skin, wings, and other components are the most vulnerable to fatigue failure [15]. The fatigue crack propagation (FCP) resistance of aerospace structural components is an extremely important indicator. Yin [16] and Shou [17] et al. discussed the influence of grain size on the crack growth rate of 2524 aluminum alloy. Yin suggested that within the range of low stress intensity factor $\Delta K$, the crack closure effect of the coarse grain samples was greater than that of the fine grain samples, and the grain refinement degraded the fatigue resistance. Shou demonstrated that when the grain size was between 50 and $100 \mu \mathrm{m}$, the crack growth rate was relatively low, and the crack growth path became more zigzagged. Srivatsan et al. [18] studied the effect of test temperature on the high-cycle fatigue and fracture properties of AA2524, indicating that the fatigue life decreased with the increasing test temperature. Baptista et al. [19] introduced an enhanced two-parameter exponential equation model to describe the subcritical FCP behavior of 2524-T3 aluminum alloy, which performed better than other test models. However, the aforementioned studies focused on the materials without thoroughly examining the impact of the creep age forming process.

Liu studied the fatigue behavior of creep aged AA2524 at $180^{\circ} \mathrm{C}$ and suggested that the crack growth resistance of the alloy was reduced after treatment [20]. On the contrary, the research of Wenke $\mathrm{Li}$ [21] showed that the fatigue life of AA2524 was improved after creep aging. However, his research only considered the fatigue performance of the alloy under high stress and single stress, thus the results are not considered fully representative. Therefore, it is necessary to further study the effect of microstructure evolution on the fatigue performance of the creep formed alloy.

This current study achieved initial results. In this paper, the influence of creep aging and artificial aging on the microstructure, conventional mechanical properties, and FCP resistance of AA2524 is discussed. The goals of the present work are to characterize and correlate the evolution of precipitates and FCP resistance with creep age forming, and to provide a theoretical basis for AA2524 creep age forming technology.

\section{Material and Experiments}

The experimental material was a 5-mm-thick plate of AA2524-T3 alloy (Southwest Aluminum Group Co., Ltd., Chongqing, China), with chemical compositions (in wt. $\%$ ) as follows: $4.26 \% \mathrm{Cu}$, $1.36 \% \mathrm{Mg}, 0.57 \% \mathrm{Mn}, 0.024 \% \mathrm{Zn}, 0.01 \% \mathrm{Ti}, 0.002 \% \mathrm{Cr}, 0.089 \% \mathrm{Si}$, and a balance of Al. The CAF tests were completed in a vacuum autoclave. This process is shown in Figure 1. The creep temperature was set at $160^{\circ} \mathrm{C}$ at a heating rate of $1.5^{\circ} \mathrm{C} / \mathrm{min}$, and the creep aging times were $4 \mathrm{~h}, 9 \mathrm{~h}$, and $24 \mathrm{~h}$. The artificial aging test was performed using the same aging times and temperature, but without external stress applied, which is called stress-free aging (SFA).

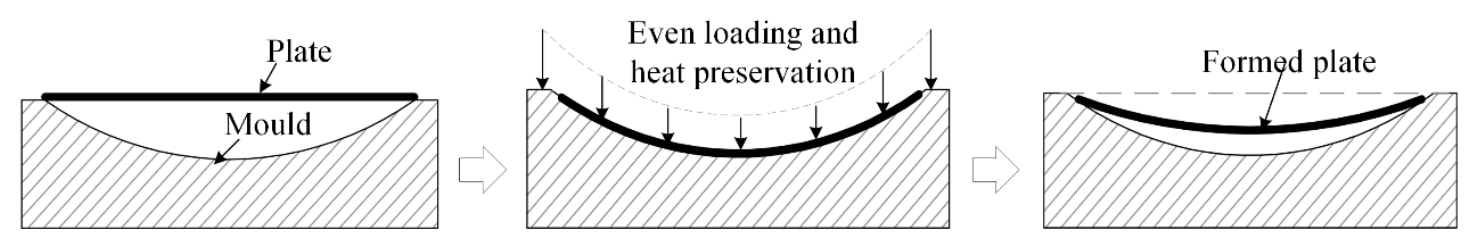

Figure 1. The process of creep age forming.

TEM observations were conducted on a Tecnai G220 (200 kV) transmission electron microscope (United States FEI limited liability company, Hillsboro, OR, USA). TEM samples were mechanically thinned to approximately 60 80 $\mu \mathrm{m}$, then punched into 3-mm diameter discs and polished in an MTP-1 twin-jet electro-polisher in a $30 \% \mathrm{HNO}_{3}$ and $70 \% \mathrm{CH}_{3} \mathrm{OH}$ mixed solution at $-30{ }^{\circ} \mathrm{C} \sim-25^{\circ} \mathrm{C}$ with a voltage of $15 \mathrm{~V}$. 
Tensile tests and FCP tests were performed on a MTS810-50 KN (MTS Systems Corporation, Eden Prairie, MN, USA) electro-hydraulic servo fatigue machine. Tensile specimens were cut in the rolling direction of the plate and tested in accordance with ASTM-E8M-2004 at room temperature, with a strain rate of $2 \mathrm{~mm} / \mathrm{min}$, resulting in an average of three samples. The FCP rate tests were conducted in ambient air at a room temperature of $18{ }^{\circ} \mathrm{C}-25^{\circ} \mathrm{C}$ and a relative humidity of $40-60 \%$ in accordance with ASTM-E647. The FCP specimens were of the compact tension (CT) geometry, as shown in Figure 2. FCP tests were characterized for constant amplitude loading at a frequency of $10 \mathrm{~Hz}$ and a stress ratio of 0.5 . Crack length was measured by using a crack opening displacement (COD) gauge, as shown in Figure 3. The hardness tests were completed on a HVS-1000Z Vickers micro digital hardness machine (Huayin Testing Instrument Co., Ltd., Yantai, China) with a holding pressure of $3 \mathrm{KN}$ for $15 \mathrm{~s}$. The average of five test points per sample was taken as the hardness value.

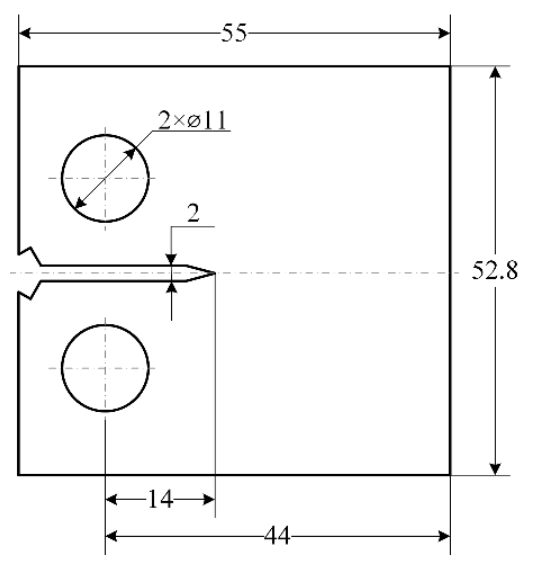

Figure 2. Compact tensile specimen (mm).

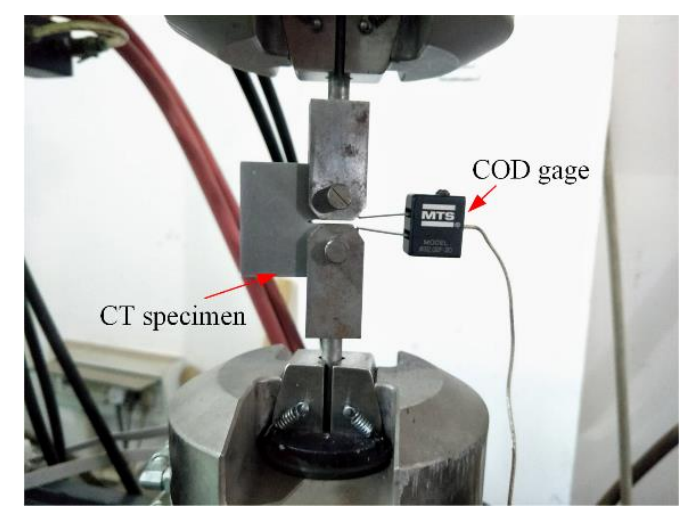

Figure 3. Fatigue crack propagation test with a crack opening displacement (COD) gauge.

\section{Results and Discussion}

\subsection{Microstructure}

The microstructures of AA2524 after creep aging and artificial aging are shown in Figure 4. The alloy contained rod-shaped Mn-rich phases (Figure $4 \mathrm{~b}$,d) and $\mathrm{Al}_{20} \mathrm{Cu}_{2} \mathrm{Mn}_{3}$ (T phases) [22-24] with a size range of $0.2 \mu \mathrm{m} \sim 0.5 \mu \mathrm{m}$. These phases were formed during a homogenizing treatment and hot rolling, and were not re-dissolved in the subsequent heat treatment. 


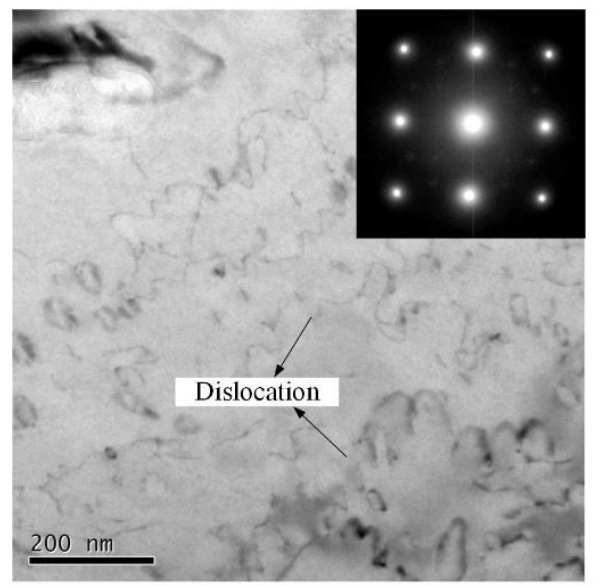

(a)

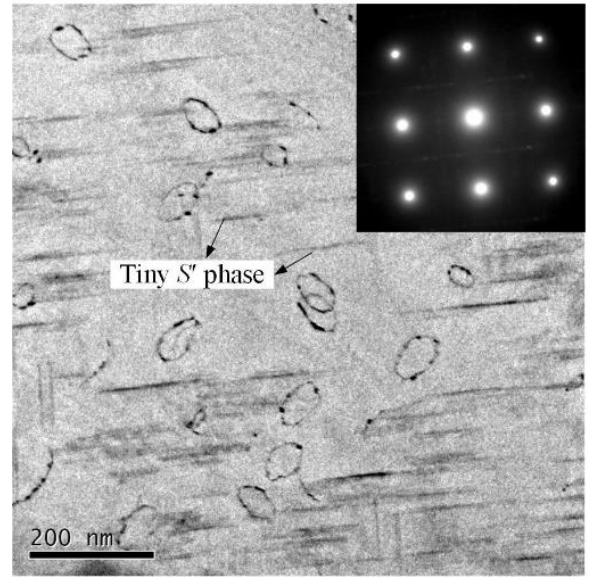

(c)

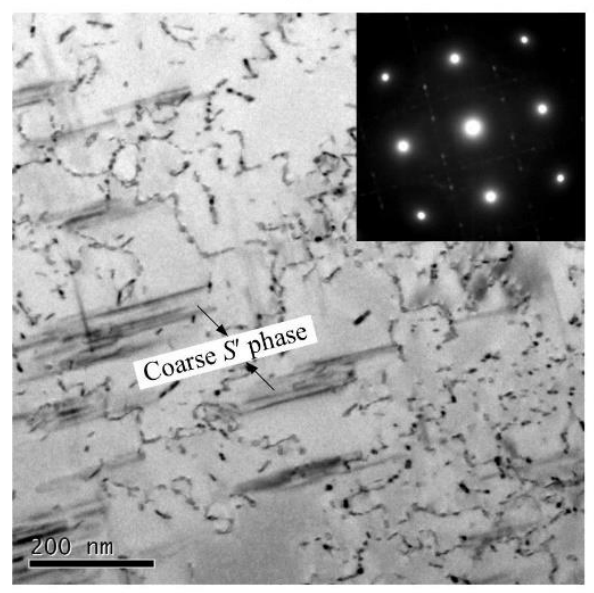

(e)

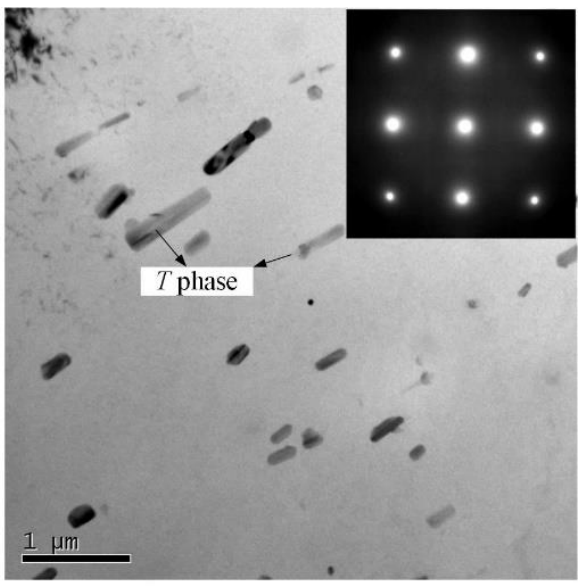

(b)

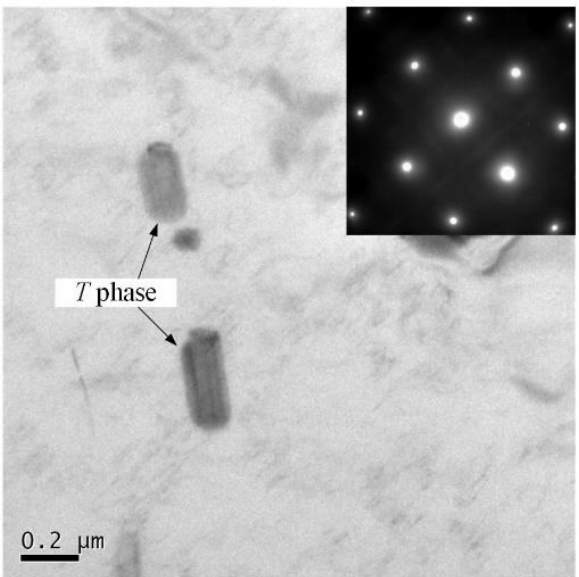

(d)

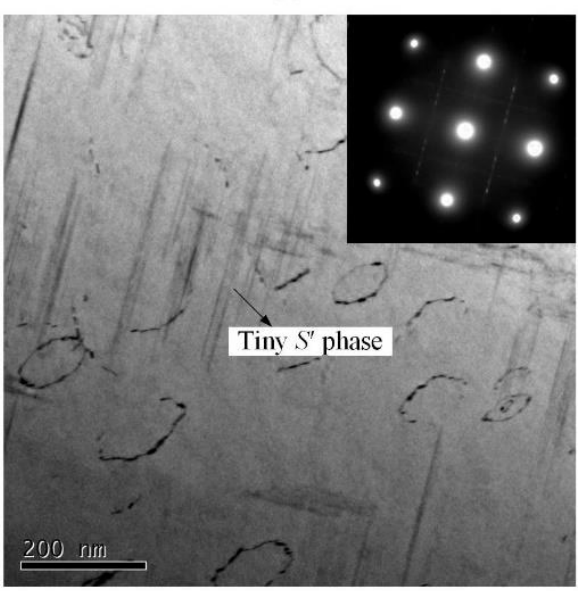

(f)

Figure 4. TEM bright field images and selected area electron diffraction (SAED) patterns along a $<100>_{\mathrm{Al}}$ zone axis for AA2524 under different aging conditions: (a) creep aged (CAF)-4h; (b) stress-free aged (SFA)-4h; (c) CAF-9h; (d) SFA-9h; (e) CAF-24h; (f) SFA-24h.

Precipitates were not observed in the TEM bright field images of the alloy that was creep aged for $4 \mathrm{~h}$ (CAF-4h) (Figure 4a), but it was discovered that tiny S" phases began to appear in the selected area electron diffraction (SAED) pattern in a $\langle 100\rangle_{\mathrm{Al}}$ direction (Figure $5 \mathrm{a}$ ). The $\mathrm{S}^{\prime \prime}$ phase is a precursor of the $\mathrm{S}^{\prime}$ phase, and generally occurs in the early aging stage of the $\mathrm{Al}-\mathrm{Cu}-\mathrm{Mg}$ alloy. It is difficult to observe the $S^{\prime \prime}$ phases in the TEM bright field image [25] because they are only several nanometers in size and there is an ambiguous interface with the matrix. As these $S^{\prime \prime}$ phases appeared, a large 
number of dislocation loops and helical dislocation lines were observed in the grains (CAF-4h) (Figure 4a). However, no obvious precipitate was observed in the alloy that was stress-free aged for $4 \mathrm{~h}$ (SFA-4h) (Figure 4b), and there were no apparent diffraction spots or streaks in the SAED pattern [26]. Therefore, it can be determined that the microstructures in the SFA-4h alloy were mainly $\mathrm{Cu}-\mathrm{Mg}$ clusters and Guinier-Preston (GP) regions.

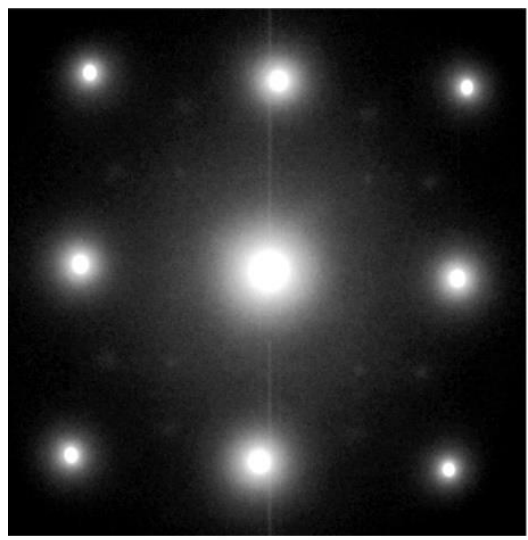

(a)

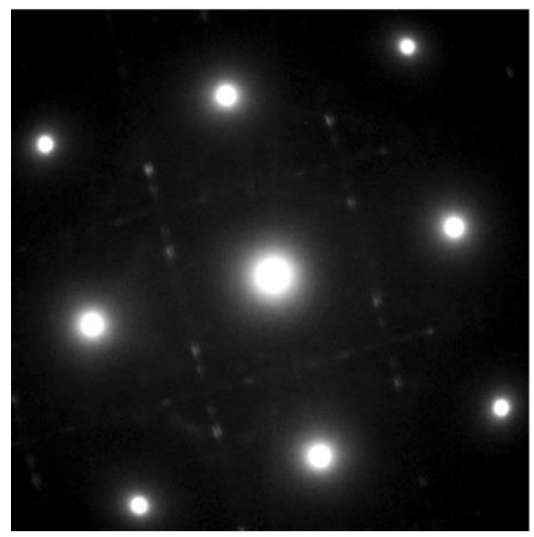

(c)

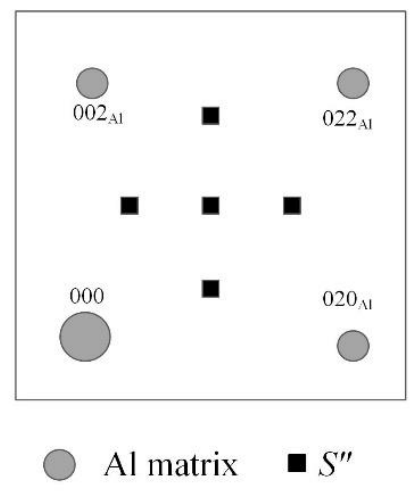

(b)

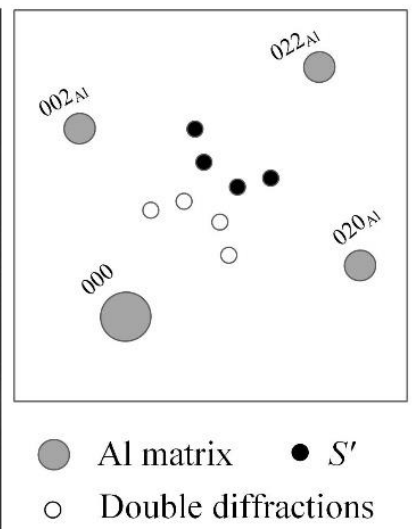

(d)

Figure 5. SAED patterns along a $<100\rangle_{\mathrm{Al}}$ zone axis and corresponding schematic diagrams for AA2524: (a,b) CAF-4h; (c,d) CAF-24h.

Large quantities of needle-shaped, fine transition phases - the densely distributed $\mathrm{S}^{\prime}$ phases—were observed (Figure 4c) in the alloy that was creep aged for $9 \mathrm{~h}$ (CAF-9h), with sizes ranging from $150 \sim 250 \mathrm{~nm}$. The precipitates in the alloy that was stress-free aged for $9 \mathrm{~h}$ (SFA-9h) were still not evident in the bright field images (Figure $4 \mathrm{~d}$ ). After creep aging for $24 \mathrm{~h}$ (CAF-24h), the precipitates continued to grow and thicken, reaching sizes of about 200 400 nm (Figure 4e), and the clearance between precipitates widened significantly. From the SAED pattern in Figure 5c, it is inferred that the main strengthening phase in grains occurs in the $S^{\prime}$ phase. In the alloy that was stress-free aged for $24 \mathrm{~h}$ (SFA-24h), precipitates with sizes of about $200 \mathrm{~nm} 300 \mathrm{~nm}$ occurred (Figure 4f), which were smaller than those found in the CAF-24h alloy (Figure 4e). The precipitation behavior shows that the presence of stress during creep aging promoted the precipitation. Some scholars contend that a great deal of nucleation precipitates from the high-density dislocations that are caused by creep stress. Then, these dislocations act as fast diffusion channels to aggregate the solute atoms toward heterogeneous nucleation, thus promoting the growth of $S^{\prime}$ phases [27].

Figure 6 shows the grain boundary feature of AA2524 samples that were creep aged and artificially aged for $9 \mathrm{~h}$ and $24 \mathrm{~h}$. There was no apparent precipitation-free zone (PFZ) at the grain boundary (Figure 6a,c) in either the CAF-9h or SFA-9h alloys, and the precipitates at the grain boundary showed discontinuous distribution. After aging for $24 \mathrm{~h}$, a distinct PFZ (Figure 6d) with a width of about 
$184 \mathrm{~nm}$ appeared at the grain boundary in the SFA-24h sample, while the PFZ (Figure 6b) in the CAF-24h sample was $140 \mathrm{~nm}$ wide-narrower than that of the stress-free aged sample. From this, it can be explained that creep stress generates a large number of dislocations in grains. These dislocations promote the surrounding preferential precipitation, resulting in more uniform precipitation kinetics of the strengthening phases in grains and grain boundaries, thus narrowing the PFZ.

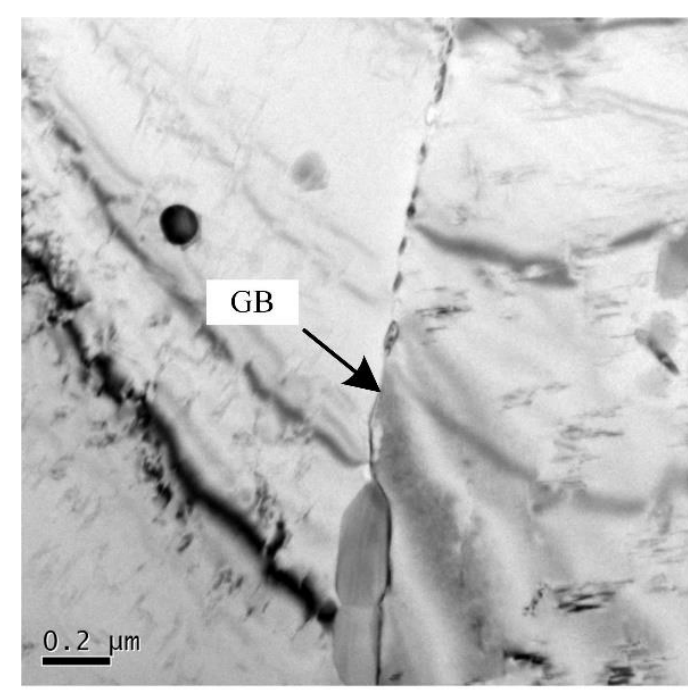

(a)

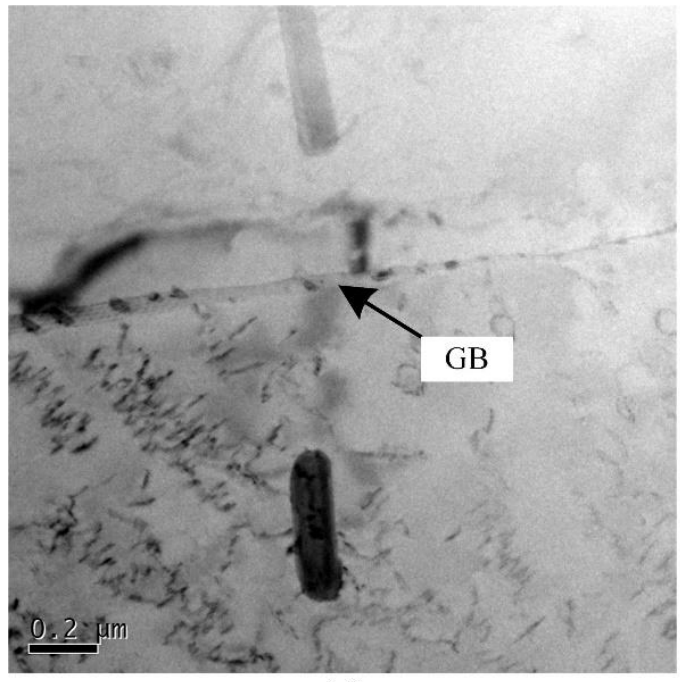

(c)

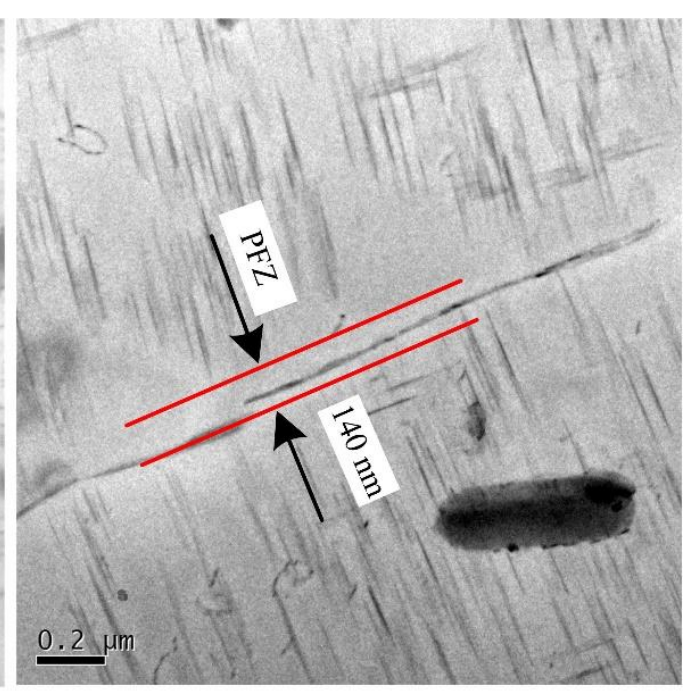

(b)

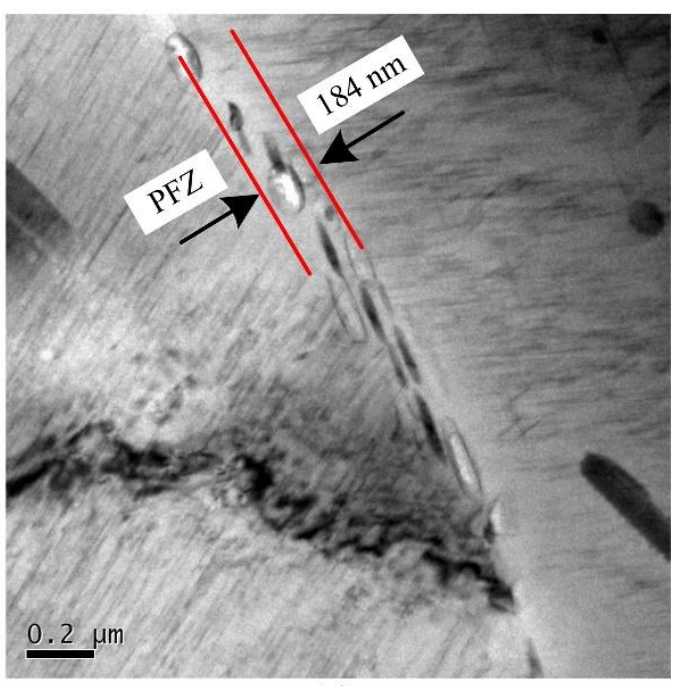

(d)

Figure 6. TEM images of AA2524 at the grain boundary under different treatment: (a) CAF-9h; (b) CAF-24h; (c) SFA-9h; (d) SFA-24h.

\subsection{Conventional Mechanical Properties}

Figures 7 and 8 show the conventional mechanical properties for AA2524 under creep aging and stress-free aging, respectively. As the aging time increased, the hardness of AA2524 first increased and then decreased (Figure 7), clearly reflecting characteristics that occur at three aging stages: under aging ( $4 \mathrm{~h}$ of aging), peak aging (9 $\mathrm{h}$ of aging), and over aging ( $24 \mathrm{~h}$ of aging). For the stress-free aged alloy, the hardness decreased within the aging time of $0 \mathrm{~h} \sim 4 \mathrm{~h}$ (Figure 7 ) and increased from $9 \mathrm{~h}$ to $24 \mathrm{~h}$. However, the hardness changed slightly during the $4 \mathrm{~h} \sim 9 \mathrm{~h}$ range of time, indicating an apparent plateau region. The study done by Ringer et al. [28] on the low $\mathrm{Cu} / \mathrm{Mg}$ ratio Al-Cu-Mg alloy confirmed that the hardening curves of the Al-Cu-Mg alloy, at an aging temperature ranging from $100{ }^{\circ} \mathrm{C}$ to $240{ }^{\circ} \mathrm{C}$ and within an $\alpha-\mathrm{S}$ phase region, displayed an obvious plateau region. Experimental results 
in the present paper are consistent with this conclusion. In contrast, there was no hardness plateau region under creep aging. After aging for $9 \mathrm{~h}$, the hardness of the CAF-9h alloy rapidly reached a peak value of $159 \mathrm{HV}, 16.9 \%$ higher than that of the SFA-9h alloy $(136 \mathrm{HV})$. This indicates that creep aging significantly accelerates the hardening rate and improves the hardness of the alloy.

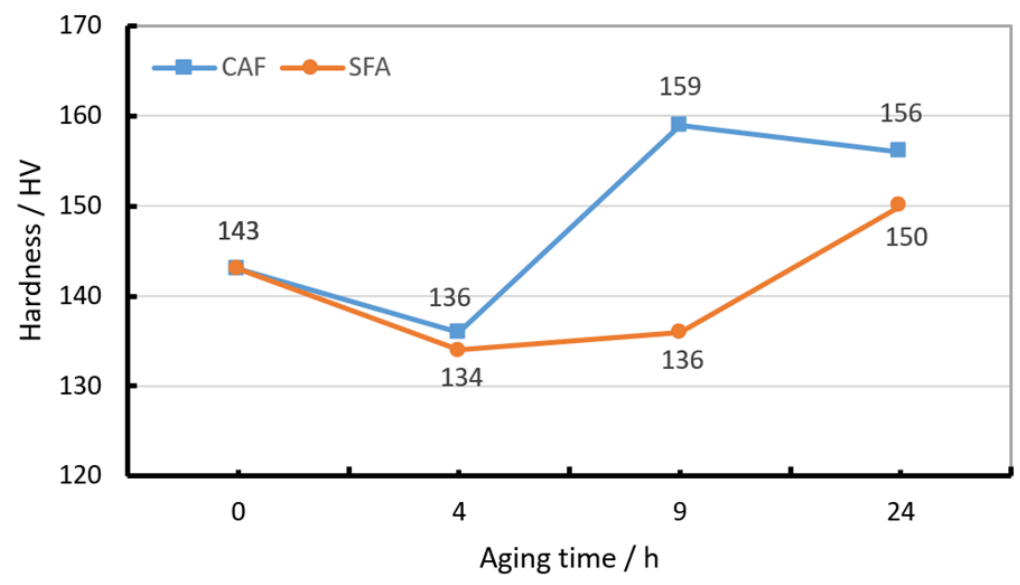

Figure 7. Hardness of AA2524 under creep age forming and artificial aging.

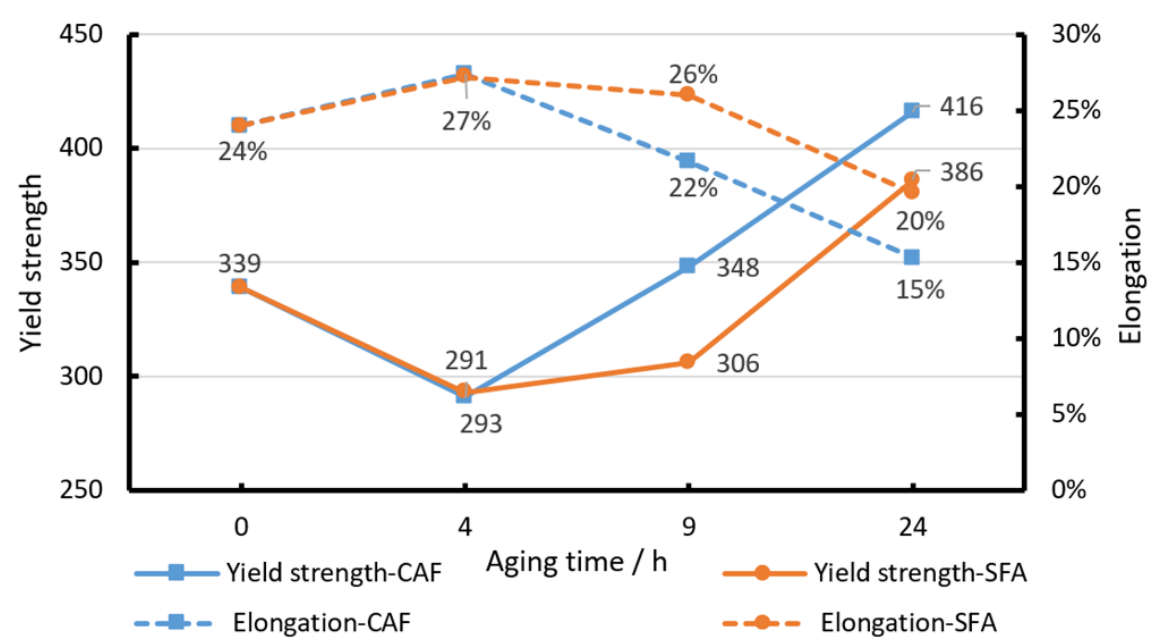

Figure 8. Yield strength and elongation of AA2524 under creep age forming and artificial aging.

After $4 \mathrm{~h}$ of aging, the yield strength $\left(\sigma_{0.2}\right)$ of AA2524 had significantly degraded compared to AA2524-T3, the $0 \mathrm{~h}$ artificially aged alloy (Figure 8). With the increased aging time, the yield strength of the alloy was on the rise. With the same aging time, the yield strength of the creep aged alloys was higher than that of the artificially aged alloys. The yield strengths of the CAF-9h and CAF-24h alloys were $13.7 \%$ and $7 \%$ higher than those of the SFA-9h and SFA-24h alloys, respectively. All of the alloys were of superior plasticity, with an elongation $(\delta)$ above $15 \%$. The variation trend of elongation was opposite that of the change in yield strength. Elongation of the $4 \mathrm{~h}$ aged alloys reached its highest point at $27 \%$, followed by a downward trend. Compared with artificial aging, creep aging degraded the elongation of the alloy. After aging for $9 \mathrm{~h}$, the elongation of the CAF-9h alloy was $18.2 \%$ lower than that of the artificially aged $9 \mathrm{~h}$ (AA-9h) alloy.

The changes in the mechanical properties of the alloy are closely related to its microstructure characteristics [29]. According to the aforementioned TEM observations, the main strengthening phases of AA2524 are the needle-shaped $S\left(S^{\prime}\right)$ phases, which can improve the strength and hardness but reduce the plasticity. The sizes of precipitates in the CAF-9h alloy (Figure 4c) were larger than those in the SFA-9h alloy (Figure 4d), and the effect of precipitation strengthening was more pronounced. 
Therefore, creep aged alloys boast higher tensile strength and hardness than stress-free aged alloys, but lower elongation.

\subsection{Fatigue Crack Growth Behavior}

Figure 9 shows the FCP rate of AA2524 under different creep aging conditions. The fatigue crack growth behavior can be divided into three stages. In the low stress region of $\Delta K \leq 7 \mathrm{MPa} \cdot \mathrm{m}^{1 / 2}$, the FCP rates of different creep aged specimens varied significantly, among which the FCP rate of the CAF-4h specimen was the lowest. With the increased aging time, the FCP rate was accelerated, and the FCP rate of the CAF-24h specimen was the highest. This difference was mainly related to the characteristics of precipitates and dislocation slips in the alloy matrix. However, with the increase of the stress intensity factor range $\Delta K$, the FCP rates in the Paris region and the rapid fracture region tended to be consistent under different aging treatments, indicating that the effect of precipitate features in the alloy matrix on crack propagation resistance was no longer pronounced.

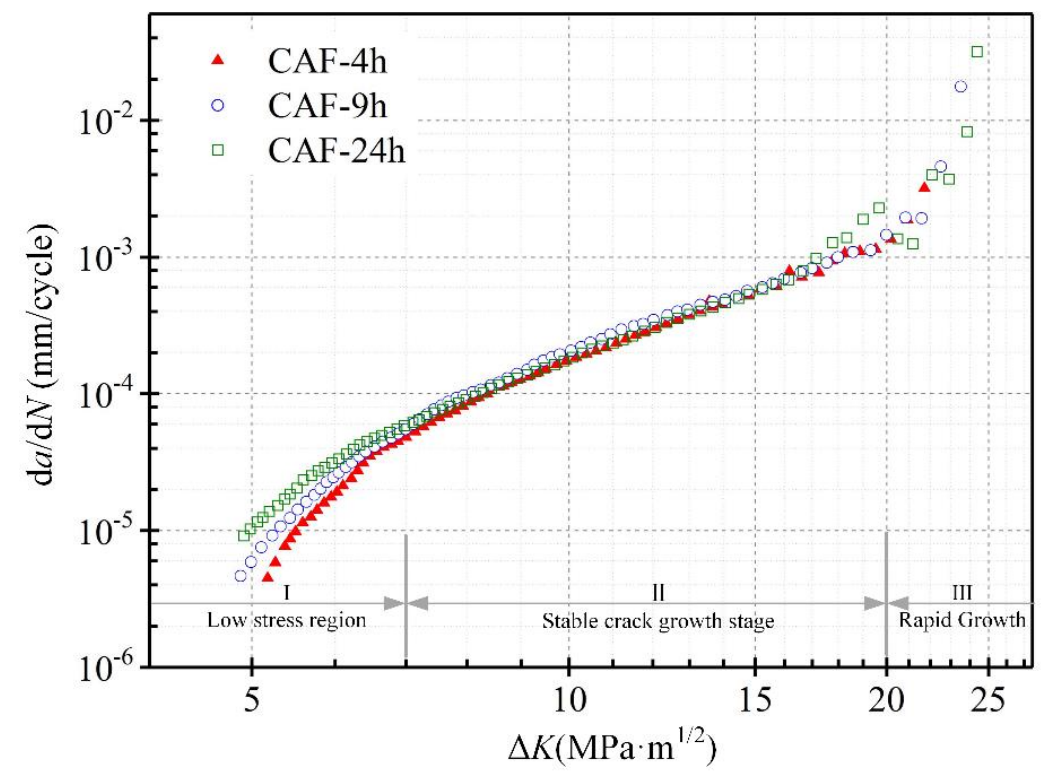

Figure 9. Fatigue crack growth rates of AA2524 under different creep age forming conditions.

The CAF-4h alloy mainly contained fine S" phases (Figure 4a), Cu-Mg clusters, and GP zones. These coherent clusters promoted the planar slip of dislocations under cyclic loading, which greatly increased the reversibility of dislocation slip, reduced the accumulation of fatigue damage, and improved the fatigue resistance of the alloy. The precipitates in both the CAF-9h and CAF-24h alloys were mainly needle-shaped $S^{\prime}$ phases (Figure $4 c, e$ ), with larger sized $S^{\prime}$ phases in the CAF-24 $\mathrm{h}$ alloy. These needle-shaped coarse phases changed the dislocation slip mode from single slip to cross slip, which degraded the reversibility of dislocation slip and accelerated the FCP rate. A PFZ appeared in the grain boundary of the CAF-24h alloy (Figure 6b), leading to a decrease in the grain boundary strength. These softer PFZs caused stress concentration around the grain boundary and accelerated the FCP rate [30]. To summarize, PFZs and larger needle-shaped precipitates lead to the highest FCP rate of the CAF-24h alloy.

In the stable crack growth stage-namely when $\Delta K=7 \sim 16 \mathrm{MPa} \cdot \mathrm{m}^{1 / 2}$-the Paris region precipitates, with a higher $\Delta K$ level, showed a weakened effect on the FCP rate. Figure 9 displays that the crack growth rate of the CAF-9h sample was slightly higher, but the difference in FCP rates under these three conditions was much smaller than that of the low $\Delta K$ level. When $\Delta K \geq 16 \mathrm{MPa} \cdot \mathrm{m}^{1 / 2}$, $\mathrm{d} a / \mathrm{dN} \geq 10^{-3} \mathrm{~mm} /$ cycle, and the $\mathrm{d} a / \mathrm{dN}-\Delta K$ curves showed an apparent knee, this indicated that the crack propagation had entered a rapid growth stage. 
Figure 10 shows a comparison between the FCP rates of creep aged and stress-free aged AA2524 for aging times of $4 \mathrm{~h}, 9 \mathrm{~h}$, and $24 \mathrm{~h}$. In Figure 10a, the FCP rates of $4 \mathrm{~h}$ aged alloys under two different aging conditions were very close because both alloys contained $\mathrm{Cu}-\mathrm{Mg}$ clusters and GP zones (Figure $4 a, b$ ). Although fine $\mathrm{S}^{\prime \prime}$ phases could be found in the SAED pattern of the CAF-4h alloy, these phases had little influence on the FCP rate of the alloy due to the $S^{\prime \prime}$ phases remaining coherent with the matrix. As seen in Figure 10b,c, after aging for $9 \mathrm{~h}$ and $24 \mathrm{~h}$, the FCP rates of the creep aged alloys were significantly higher in the low stress intensity factor region than those of the stress-free aged alloys.

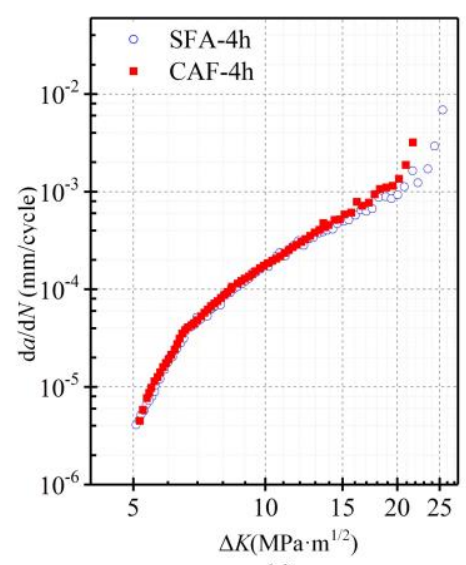

(a)

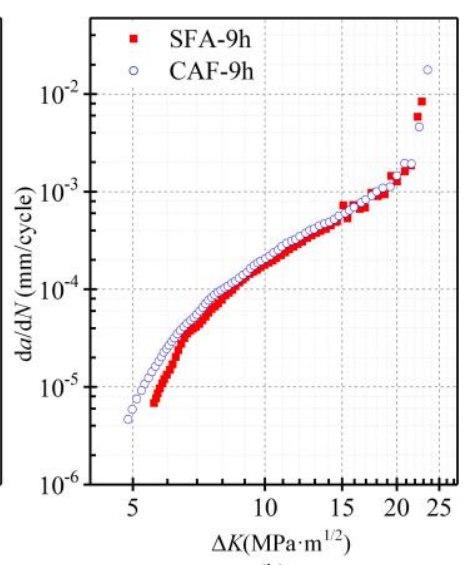

(b)

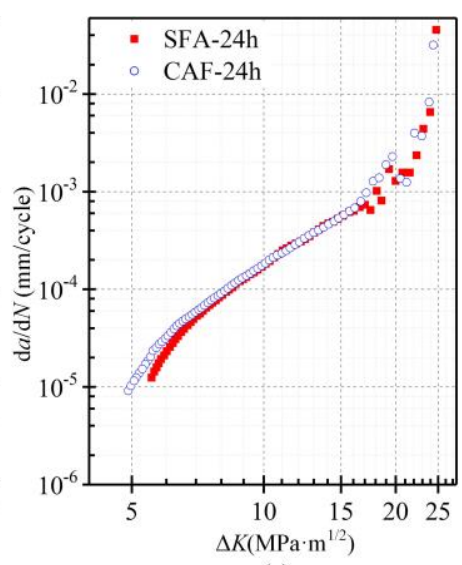

(c)

Figure 10. Comparison of the fatigue crack propagation (FCP) rates of creep aged and stress-free aged AA2524 for various aging times: (a) $4 \mathrm{~h}$; (b) $9 \mathrm{~h}$; (c) $24 \mathrm{~h}$.

After $9 \mathrm{~h}$ of aging, needle-shaped $\mathrm{S}^{\prime}$ phases that were semi-coherent with the matrix (Figure $4 \mathrm{c}, \mathrm{d}$ ) mainly precipitated. However, the presence of stress in the creep aging process promoted the precipitation, so the sizes of the $S^{\prime}$ phases in the CAF-9h alloy were larger. Under the cyclic loading, dislocations could not cut through part of the coarse $\mathrm{S}^{\prime}$ phases and instead bypassed them, thus reducing the reversibility of cyclic slip, accumulating a large plastic deformation at the crack tip, and promoting crack propagation. In the region of $\Delta K \leq 7.5 \mathrm{MPa} \cdot \mathrm{m}^{1 / 2}$, the fatigue crack propagation resistance of the CAF-9h alloy was lower than that of the SFA-9h alloy.

After $24 \mathrm{~h}$ of aging, the sizes of precipitates showed a similar rule (Figure $4 \mathrm{e}-\mathrm{f}$ ). In the low stress region, the FCP rate of the SFA-24h alloy was lower than that of the CAF-24h alloy. However, the PFZ in the grain boundaries of the SFA-24h alloy (Figure 6d) was wider than it was (Figure 6b) in the CAF-24h alloy, which accelerated the FCP rate to some extent. Under the influence of both precipitates and PFZs, the effect of microstructures on the FCP resistance disappeared in advance. Therefore, the $\mathrm{d} a / \mathrm{d} N-\Delta K$ curves of the two alloys (SFA-24h and CAF-24h) were basically consistent when $\Delta K \geq 7 \mathrm{MPa} \cdot \mathrm{m}^{1 / 2}$.

In the lower stress region, we chose to analyze the corresponding fatigue fracture at $\Delta K=6 \mathrm{MPa} \cdot \mathrm{m}^{1 / 2}$, in which the crack was in the stable growth stage. Under the SEM, a large area of regular and parallel fatigue striations could be observed, as shown in Figure 11. When encountering the particles in the matrix, the striations would bypass the particles and continue to expand (Figure 11b,c), as the crack propagation direction conveys with the dotted arrow in Figure 11. The width of fatigue striations marked in Figure 11 shows the general rule that the width of fatigue striations increases with the increasing creep time. The fatigue striation width of the creep aged specimen was larger than that of the stress-free aged one when tested with the same aging time. The fatigue striation was caused by the repeated sharpening of the crack tip during the cyclic loading. The fatigue striation width corresponds to the length of a certain cyclic fatigue crack propagation, which can represent the fatigue crack growth rate to some extent. That is, the larger the fatigue striation width, the higher the fatigue crack growth rate. This conclusion is also consistent with the previous $\mathrm{d} a / \mathrm{d} N-\Delta K$ curve analysis. 


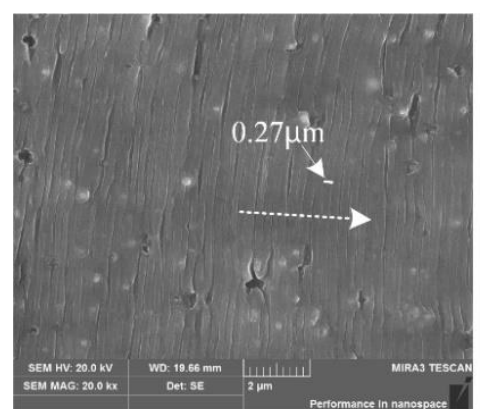

(a)

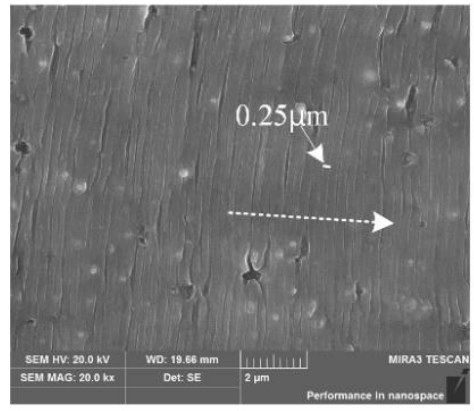

(d)

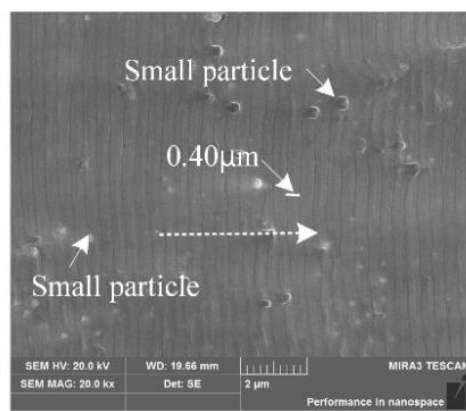

(b)

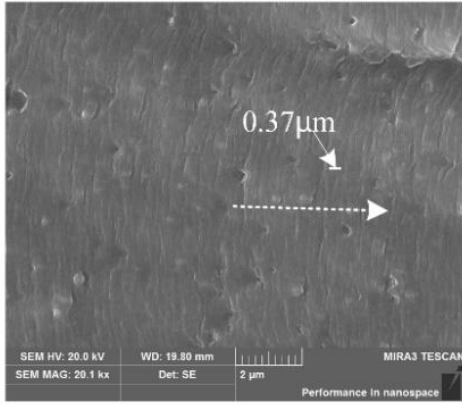

(e)

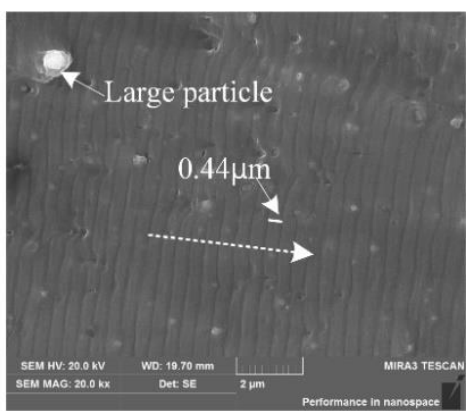

(c)

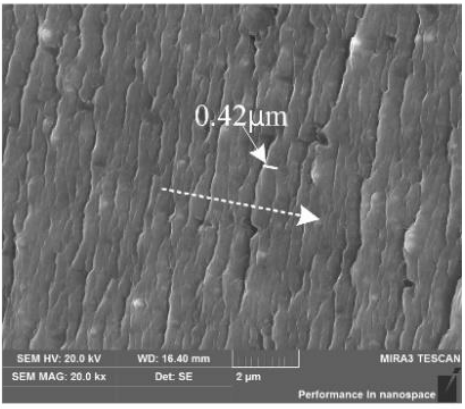

(f)

Figure 11. Fatigue striation morphology at fractures of different specimens when $\Delta K=6 \mathrm{MPa} \cdot \mathrm{m}^{1 / 2}$ : (a) CAF-4h; (b) CAF-9h; (c) CAF-24h; (d) SFA-4h; (e) SFA-9h; (f) SFA-24h.

It can be concluded that the FCP rate of AA2524 in the low stress region is mainly affected by the precipitate features. With the increase of $\Delta K$, precipitates gradually show a weakened effect on the FCP rate, while PFZs in the grain boundaries accelerate the FCP of the alloy to some extent.

\section{Conclusions}

(1) Creep age forming generated a large quantity of dislocations in the grains of AA2524, which provided nucleation locations for the heterogeneous nucleation of the second phase. The resulting precipitates in the creep aged AA2524 were larger in number and size than those in the stress-free aged AA2524 after the same aging time.

(2) The yield strength of AA2524 increased with increasing aging time. After the same aging time, the yield strength of the creep aged alloy was higher, while the hardening curve of the stress-free aged alloy had a plateau region for approximately $5 \mathrm{~h}$. This indicates that creep aging can significantly accelerate the age hardening process, with the alloy quickly reaching the peak aging state.

(3) In the low stress intensity factor region, the crack growth behavior of AA2524 was mainly affected by precipitates. The FCP rate was accelerated with an increased creep aging time. Creep aging promoted the precipitation and growth of $S^{\prime \prime}$ and $S^{\prime}$ phases in the alloy. The needle-shaped coarse $\mathrm{S}^{\prime \prime}\left(\mathrm{S}^{\prime}\right)$ phases altered dislocation slip mode in the alloy, reduced the reversibility of dislocation slips, and degraded the crack propagation resistance. The FCP rate of the creep aged alloy was higher than that of the stress-free aged alloy after the same aging time.

(4) In the stable crack propagation region, the FCP rates were generally consistent under different aging treatments, and the effect of precipitate features in the alloy matrix on crack propagation resistance was negligible.

Author Contributions: C.L. and Y.L. conceived and designed the experiment; C.L., Q.W. performed the experiments; C.L., L.M., and X.Z. analyzed the data; S.L. and X.Z. contributed reagents, materials, and analysis tools; C.L. wrote the paper; M.L. was responsible for the revision. 
Funding: This work was supported by the National Natural Science Foundation of China (No. 51375500), the Fundamental Research Funds for the Central Universities of Central South University (No. 2015zzts038), Hebei Provincial Science and Technology Plan Self-Financing Project (No. 17211828), Hebei Province Higher Education Science and Technology Research Youth Fund Project (QN2018013), and the Hunan Science and Technology Plan Project (No. 2016GK2005).

Conflicts of Interest: The authors declare no conflicts of interest.

\section{References}

1. Nakai, M.; Eto, T. New aspect of development of high strength aluminum alloys for aerospace applications. Mater. Sci. Eng. A 2000, 285, 62-68. [CrossRef]

2. Starke, E.A., Jr.; Staley, J.T. Application of modern aluminum alloys to aircraft. Prog. Aerosp. Sci. 1996, 32, 131-172. [CrossRef]

3. Warner, T. Recently-developed aluminium solutions for aerospace applications. Mater. Sci. Forum 2006, 519, $1271-1278$. [CrossRef]

4. Zeng, Y.; Huang, X. Forming technologies of large integral panel. Acta Aeronaut. Et Aeronaut. Sin. 2008, $29,721-727$.

5. Zhan, L.; Lin, J.; Dean, T.A. A review of the development of creep age forming: Experimentation, modelling and applications. Int. J. Mach. Tools Manuf. 2011, 51, 1-17. [CrossRef]

6. Watcham, K.; Watcham, K.; Watcham, K. Airbus A380 takes creep age-forming to new heights. Mater. World 2004, 12, 10-11.

7. Holman, M.C. Autoclave age forming large aluminum aircraft panels. J. Mech. Work. Technol. 1989, 20, 477-488. [CrossRef]

8. Liu, X. Forecasts on crucial manufacturing technology develeopment of heavy lift launch vehicle. Aerosp. Manuf. Technol. 2013, 1, 002.

9. Jeunechamps, P.P.; Ho, K.C.; Lin, J.; Ponthot, J.P.; Dean, T.A. A closed form technique to predict springback in creep age-forming. Int. J. Mech. Sci. 2006, 48, 621-629. [CrossRef]

10. Zhan, L.; Lin, J.; Dean, T.A.; Huang, M. Experimental studies and constitutive modelling of the hardening of aluminium alloy 7055 under creep age forming conditions. Int. J. Mech. Sci. 2011, 53, 595-605. [CrossRef]

11. Zhang, J.; Zhang, S.N.; Liang, E.W. Blazar anti-sequence of spectral variation within individual blazars: Cases for Mrk 501 and 3C 279. Astrophys. J. 2013, 767, 8. [CrossRef]

12. Liu, L.; Zhan, L.; Li, W. Creep aging behavior characterization of 2219 aluminum alloy. Metals 2016, 6, 146. [CrossRef]

13. Jeshvaghani, R.A.; Zohdi, H.; Shahverdi, H.R.; Bozorg, M.; Hadavi, S.M.M. Influence of multi-step heat treatments in creep age forming of 7075 aluminum alloy: Optimization for springback, strength and exfoliation corrosion. Mater. Charact. 2012, 73, 8-15. [CrossRef]

14. Xu, Y.; Zhan, L.; Li, W. Effect of pre-strain on creep aging behavior of 2524 aluminum alloy. J. Alloys Compd. 2017, 691, 564-571. [CrossRef]

15. Schijve, J. Fatigue damage in aircraft structures, not wanted, but tolerated? Int. J. Fatigue 2009, 31, 998-1011. [CrossRef]

16. Yin, D.; Liu, H.; Chen, Y.; Yi, D.; Wang, B.; Wang, B.; Shen, F.; Fu, S.; Tang, C.; Pan, S. Effect of grain size on fatigue-crack growth in 2524 aluminium alloy. Int. J. Fatigue 2016, 84, 9-16. [CrossRef]

17. Shou, W.B.; Yi, D.Q.; Liu, H.Q.; Tang, C.; Shen, F.H.; Wang, B. Effect of grain size on the fatigue crack growth behavior of 2524-T3 aluminum alloy. Arch. Civil Mech. Eng. 2016, 16, 304-312. [CrossRef]

18. Srivatsan, T.S.; Kolar, D.; Magnusen, P. The cyclic fatigue and final fracture behavior of aluminum alloy 2524. Mater. Des. 2002, 23, 129-139. [CrossRef]

19. Baptista, C.A.R.P.; Adib, A.M.L.; Torres, M.A.S.; Pastoukhov, V.A. Describing fatigue crack growth and load ratio effects in Al 2524 T3 alloy with an enhanced exponential model. Mech. Mater. 2012, 51, 66-73. [CrossRef]

20. Liu, C.; Liu, Y.; Li, S.; Ma, L.; Zhao, X.; Wang, Q. Effect of creep aging forming on the fatigue crack growth of an AA2524 alloy. Mater. Sci. Eng. A 2018. [CrossRef]

21. Li, W.; Zhan, L.; Liu, L.; Xu, Y. The effect of creep aging on the fatigue fracture behavior of 2524 aluminum alloy. Metals 2016, 6, 215. [CrossRef]

22. Chen, Y.Q.; Yi, D.Q.; Jiang, Y.; Wang, B.; Xu, D.Z.; Li, S.C. Twinning and orientation relationships of T-phase precipitates in an Al matrix. J. Mater. Sci. 2013, 48, 3225-3231. [CrossRef] 
23. Chen, Z.; Chen, P.; Li, S. Effect of Ce addition on microstructure of $\mathrm{Al}_{20} \mathrm{Cu}_{2} \mathrm{Mn}_{3}$ twin phase in an $\mathrm{Al}-\mathrm{Cu}-\mathrm{Mn}$ casting alloy. Mater. Sci. Eng. A 2012, 532, 606-609. [CrossRef]

24. Liu, C.; Liu, Y.; Ma, L.; Yi, J. Effects of solution treatment on microstructure and high-cycle fatigue properties of 7075 aluminum alloy. Metals 2017, 7, 193. [CrossRef]

25. Chen, Y.Q.; Pan, S.P.; Liu, W.H.; Cai, Z.H.; Tang, S.W.; Tang, C.P. Effect of precipitates on creep behaviors of Al-Cu-Mg alloy. Chin. J. Nonferrous Metals 2015, 25, 900-909.

26. Ringer, S.P.; Polmear, I.J.; Sakurai, T. Effect of additions of Si and Ag to ternary Al-Cu-Mg alloys in the $\alpha+\mathrm{s}$ phase field. Mater. Sci. Eng. A 1996, 217, 273-276. [CrossRef]

27. Shen, F.; Wang, B.; Yi, D.; Liu, H.; Tang, C.; Shou, W. Effects of heating rate during solid-solution treatment on microstructure and fatigue properties of AA2524 T3 Al-Cu-Mg sheet. Mater. Des. 2016, 104, 116-125. [CrossRef]

28. Ringer, S.P.; Sakurai, T.; Polmear, I.J. Origins of hardening in aged Al-Cu-Mg-(Ag) alloys. Acta Mater. 1997, 45, $3731-3744$. [CrossRef]

29. Zhan, L.H.; Yan-Guang, L.I.; Huang, M.H. Microstructures and properties of 2124 alloy creep ageing under stress. J. Cent. S. Univ. 2012, 43, 926-931.

30. Krol, T.; Baither, D.; Nembach, E. The formation of precipitate free zones along grain boundaries in a superalloy and the ensuing effects on its plastic deformation. Acta Mater. 2004, 52, 2095-2108. [CrossRef]

(C) 2018 by the authors. Licensee MDPI, Basel, Switzerland. This article is an open access article distributed under the terms and conditions of the Creative Commons Attribution (CC BY) license (http://creativecommons.org/licenses/by/4.0/). 